\title{
THE EFFECT OF AN EDUCATIONAL INTERVENTION BASED ON HEALTH BELIEF MODEL ON IMPROVING SMOKING PREVENTIVE BEHAVIORS
}

\begin{abstract}
Background and objective: Smoking is a common health problem which has involved many young people in the society. This study was done to assess the effect of a health education program considered based on the health belief model (HBM) to improve smoking preventive behaviors among 3rd-grade high school students in Nowshahr city, north of Iran.

Materials and methods: This study was a quasi-experimental study in was performed on $\mathbf{2 8 0}$ male students of 3rd-grade high schools of Nowshahr city; they were randomly allocated into experimental and control groups. Data was collected through a researcher-made questionnaire including 40 questions based on health belief model (perceived susceptibility, perceived severity, perceived benefits and perceived barriers to smoking, and cues to action) and preventive behaviours of smoking. After data collection in the first phase, health educational intervention was implemented in the second phase. Data was analyzed using SPSS 18 with descriptive and inferential (Chi Square, independent $t$ and pair t) tests.

Results: The mean score of all HBM constructs in experimental group after applying health educational intervention compared with before the implementing the intervention was significantly different $(p<0.05)$. Moreover, the mean score of all parts of HBM constructs after the intervention was significantly increased in the experimental group compared with the control group $(p<0.05)$. Conclusion: Implementing smoking preventive actions is effective on smoking preventive behaviors among high school students. Therefore, smoking prevention programs should be started before and during the high school period.

Paper Type: Research Article.

Keywords: Health Belief Model (HBM), Smoking Prevention, High School Students, Health Education, Nowshahr.
\end{abstract}

Citation: Khazaee-Pool M, Zarei F, Pashaei T, Shojaeizadeh D. The effect of an educational intervention based on Health Belief Model on improving smoking preventive behaviors among high school male students in Nowshahr. Iran $\mathrm{J}$ Health Educ Health Promot. Winter 2016;4(4): 300-308.
Maryam Khazaee-Pool

$\mathrm{PhD}$ in Health Education and Health Promotion, Assistant Professor, Dept. of Health Education and Health Promotion, School of Public Health, Zanjan University of Medical Sciences (ZUMS) Zanjan, Iran

Fatemeh Zarei

PhD in Health Education and Health Promotion, Assistant Professor, Dept. of Health Education and Health Promotion, School of Public Health, ZUMS, Zanjan, Iran

Tahereh Pashaei

$\mathrm{PhD}$ in Health Education and Health Promotion, Assistant Professor, Dept. of Public Health, School of Health, Kurdistan University of Medical Sciences, Sanandaj, Iran.

Davoud Shojaeizadeh

*PhD in Health Education and Health Promotion, Professor, Dept. of Health Education and Health Promotion, School of Public Health, Tehran University of Medical Sciences (TUMS), Tehran, Iran (Corresponding Author)

Shojae5@yahoo.com

Received: 25 November 2015

Accepted: 16 November 2016 
تأثير بونامه آموزشى مبتنى بر الكوى اعتقاد بهداشتى بر بهبود رفتارهاى بيشغيراذه از مصرف سيكار در دانش آموزان

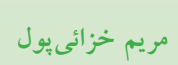
دكتراى آموزش بهداشت و ارتقاء سلامت، استاديار

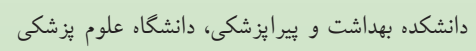

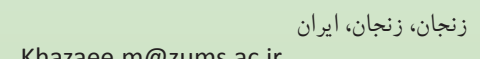

فاطمه زارعى آموزى دكتراى آموزش بهداشت و ارتقاء سلاءت، استاديار

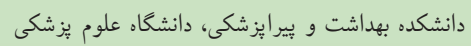
زنجان، زنجان، ايران

طاهره باشايى دكتراى آموزش بهداشت، كروه بهداشت عمومى، بهاشي

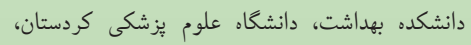
سندج، ايران داوود شجاعىزاده آئران * دكتراى آموزش بهداشت و ارتقاء سلامت، استاد

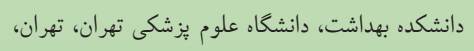
Shojae5@yahoo.com

ايران (نو يسنده مسئول)

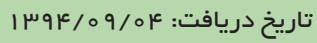
تاريخ يذيرش: تاريخ:

\section{-}

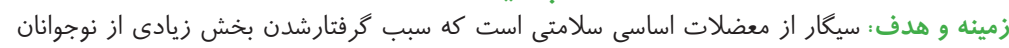

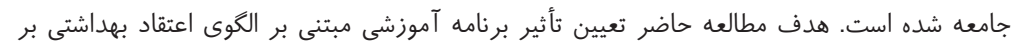

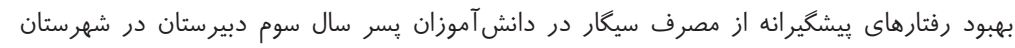
نوشهر بود.

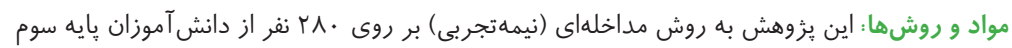

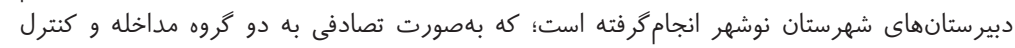

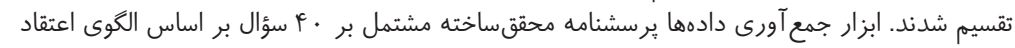

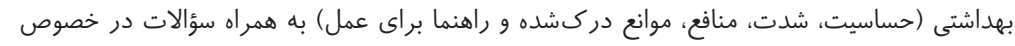

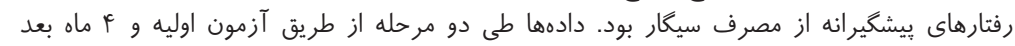

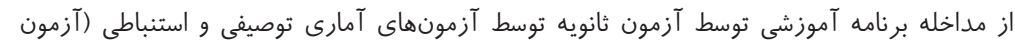

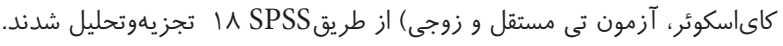

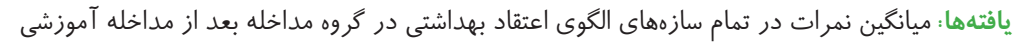

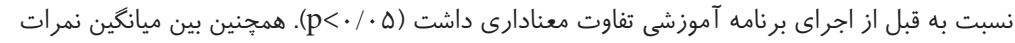

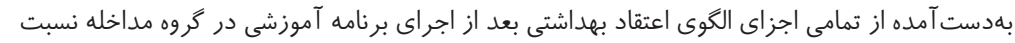

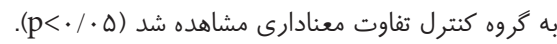

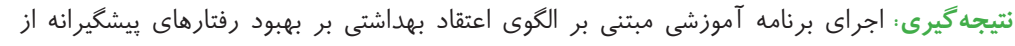

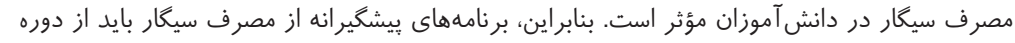

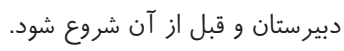

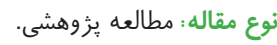
كليدوازه: الكوى اعتقاد بهداشتى، يُشيشيرى از سيكار، دانشآموزان دبيرستان، آموزش بهداشت، نوشهر.

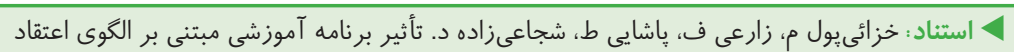

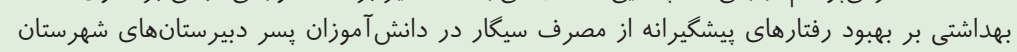

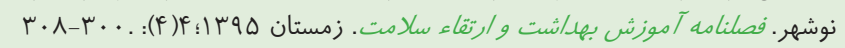


بيشكيرانه الكوى اعتقاد بهداشتى است (ه). بر اساس الخوى

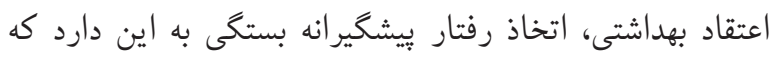

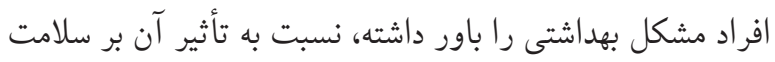

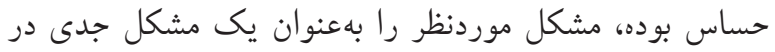

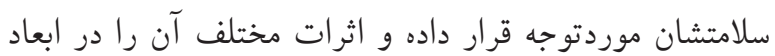
سلامت جسمى، اجتماعى، روانى و اقتصادى خود درك كنند. با دريافت راهنماهايى از محيط خود افراد نيز متقاعد شوند كه فعاليتهاى ييشخيرانه درعينحال كه بسيار مفيد و قابلاجرا

هستند، ازنظر اقتصادى نيز براى مقرونبهصرفه هستند (4).

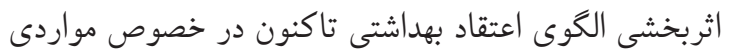

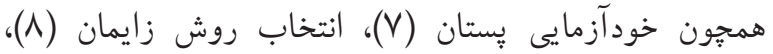

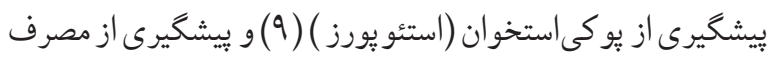

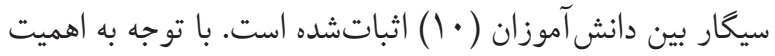

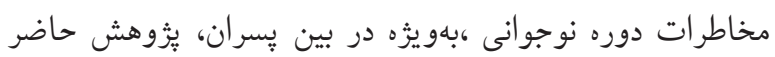

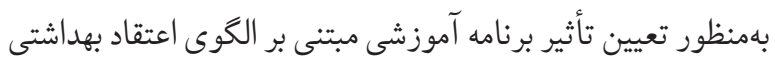

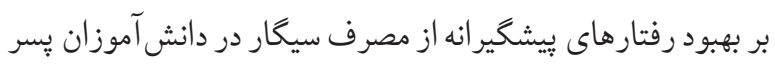
سال سوم دبيرستان در شهرستان نوشهر انجامشده است.

مو اد و روش ها يُزوهش حاضر يك مطالعه مداخلهاى از نوع نيمه تجربى بود. مطالعه

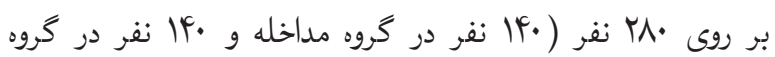
كنترل) از دانش آموزان پايه سوم دبيرستانهاى پِّرانه شهرستان

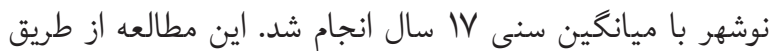

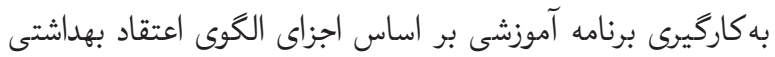

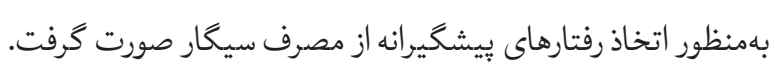
در اين مطالعه از روش نمونه گيرى جرندمرحله إى استفادهشد. نمونهها به صورت تصادفى از بين لا دبيرستان يُرانه شهرستان نوشهر، 9 دبيرستان انتخاب و با روش نمونه گيرى تصادفى ساده، ب دبيرستان براى گروه مداخله و ب دبيرستان براى گروه كنترل انتخاب شدند. در مرحله بعد به شكل تصادفى ساده از هر دبيرستان منتخب، يك برى

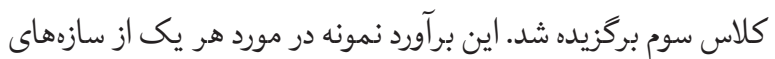
الخو (حساسيت دركشده، شدت دركشده، موانع دركشده و منافع
نوجوانى، مرحله كذر رشد جسمى و روانى فرد است؛ كه همراه با تغييرات زيستى، اجتماعى و روانشناختى است. دبيرستان، دوره

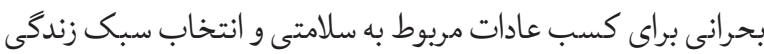

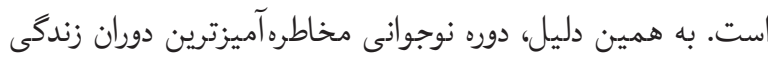
ازنظر انجام رفتارهاى برخطر همجيون شروع مصرف سيكار است. تلاش جهت كسب هويت فردى و اجتماعى، لذتجويى، كاهش اعتمادبهنفس و كمبود مهارتهاى لازم جهت ارتباط با ديخران،

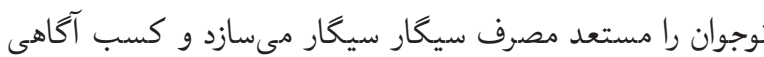

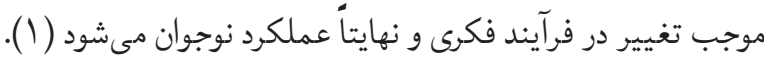
در حال حاضر، اعتياد به مصرف سيخار مشكلى جهانى و فراخير

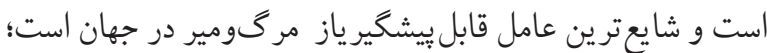

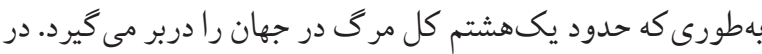

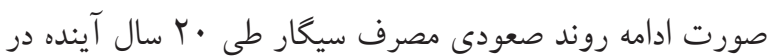

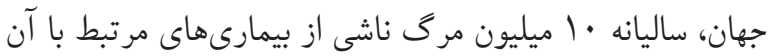

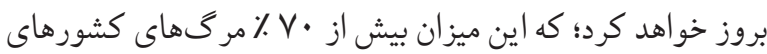

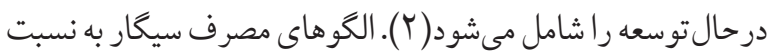

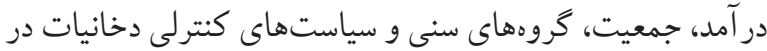
كشورهاي مختلف جهان متفاوت است. در حال حاضر يك ميليارد

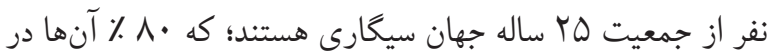
كشورهاى درحالتوسعه بسر مىبرند (广).

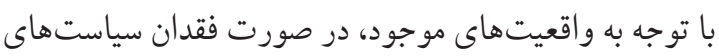

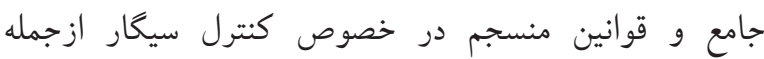

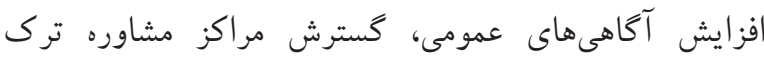

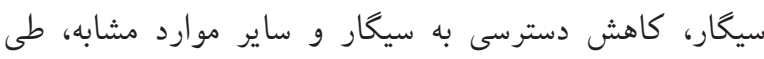

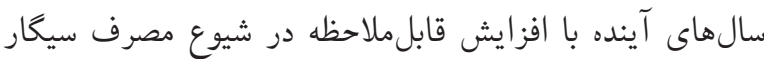

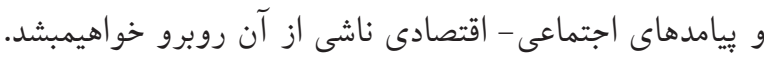

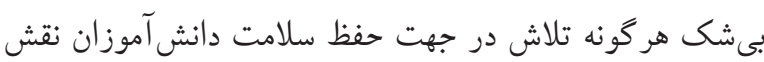

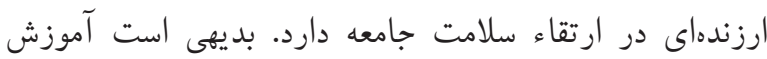

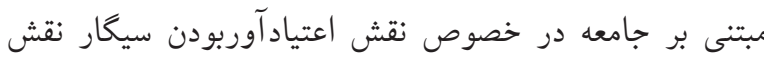
اساسى در اين خصوص دارد. بهطورى كه رويكردها و الكوهاى آموزش بهداشت دستيابى به اين هدف را تسهيل مى كند (Y).

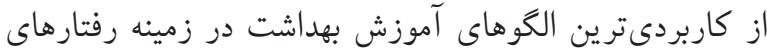


مداخله شامل برنامه آموزشى مبتنى بر سازههاى الكوى اعتقاد

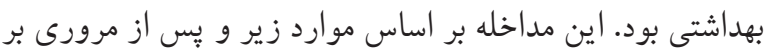

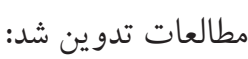

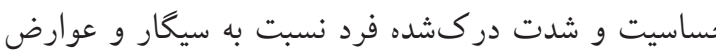
منفى ناشى از مصرف آن سبب مىشود دانشآموز رفتار

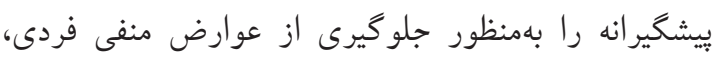
خانو ادگىى، اجتماعى و اقتصادى انجام دهد.

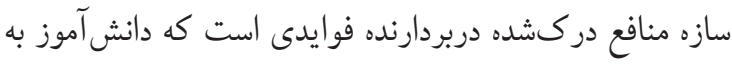
دليل انجام رفتارهاى ييشگير انه از مصرف سيخار كسب مي كند. سازه موانع دركشده كه نشاندهنده كليه مواردى است كه رئه مانع از انجام رفتار ييشخير انه در دانش آموز مى كردد.

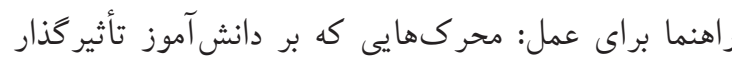

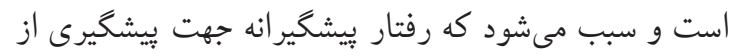
ييامدهاى منفى استعمال سيكار اتخاذ نمايد.

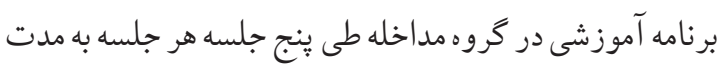
يك ساعت (در خصوص سيكار، سابقه مصرف و وضعيت موجود مصرف سيخار در ايران و جهان، عوامل تأثير كذار بر تمايلات

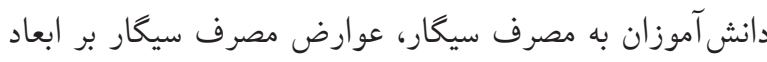

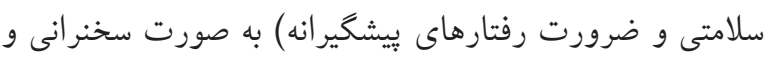

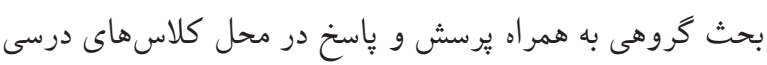

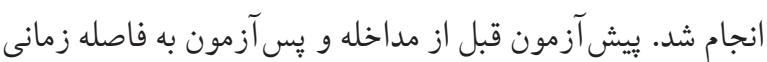
جهار ماه بعد از اجراى مداخله برنامه آموزشى اجرا شد. نتايج بهدست آمده تجزيهو تحليل و با نتايج مرحله اول مقايسه كرديد.

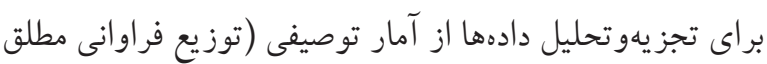

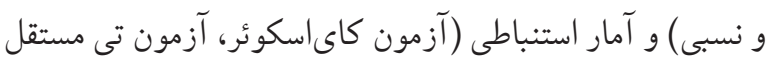

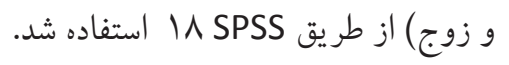

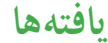

دانش آموزان كروههاى مداخله و كنترل ازنظر سن، معدل سال قبل، سريرستى خانواده، تحصيلات والدين، شغل والدين، درآمد خانوار،

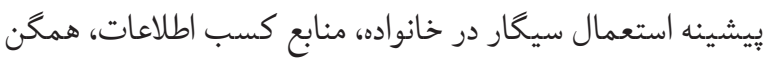

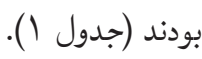

دركشده) صورت گرفت و بيشترين تعداد حجم نمونه براى موانع دركشده، يعنى •lf إنفر، در نظر گرفته شد.

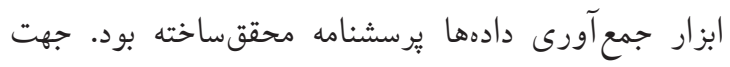

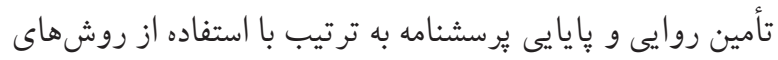

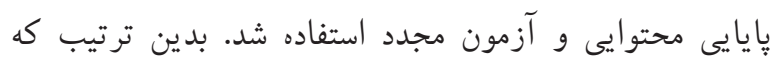

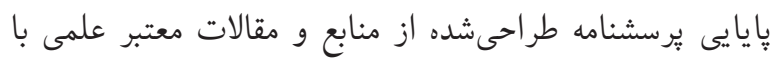

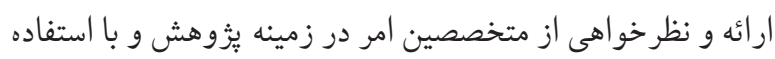

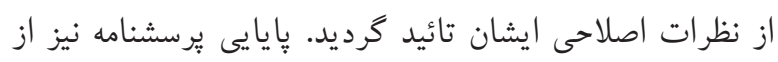

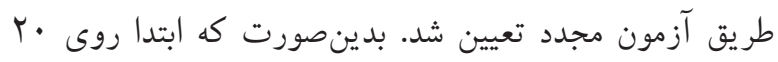

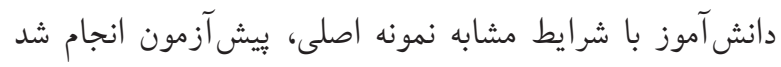

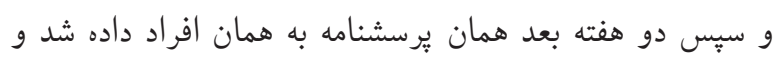

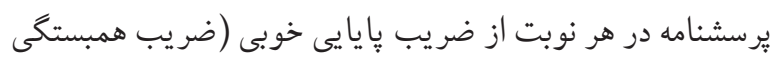
بيرسون N 1 ) برخوردار بود.

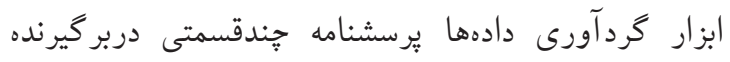

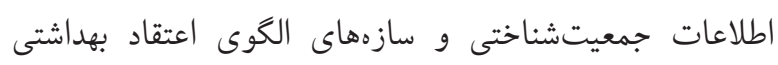

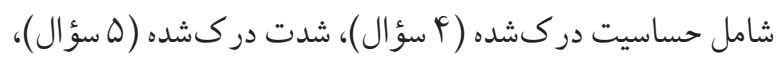

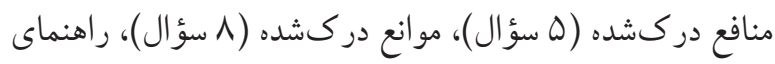

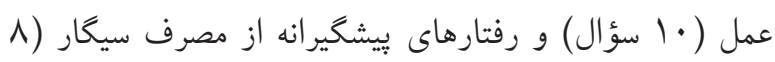

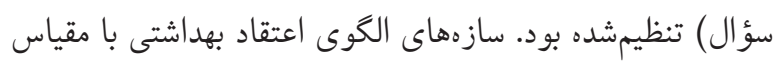

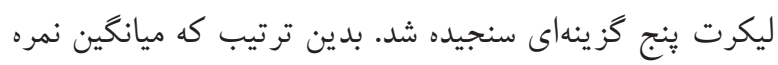

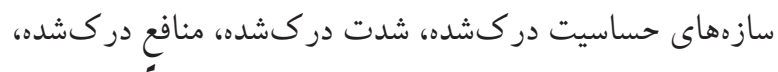

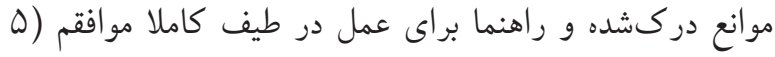

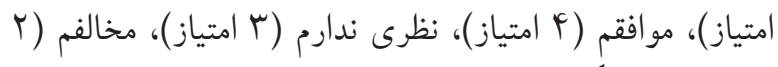

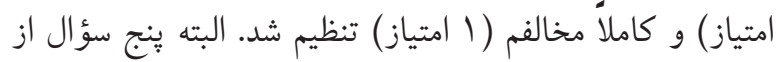

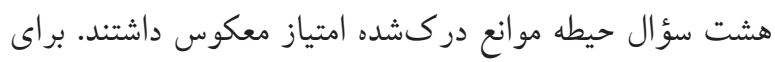

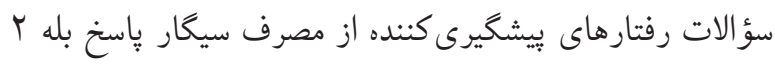
امتياز و ياسخ خير ا امتياز در نظر كرفته شد.

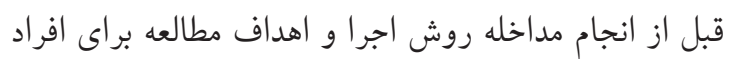

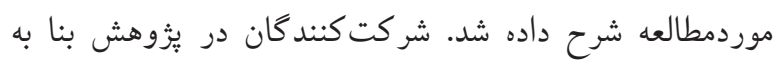
تشخيص خودشان هر وقت مىخواستند مىتوانستند از شركت

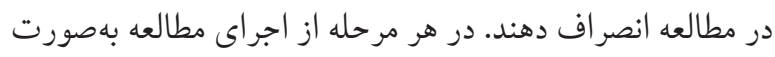
كتبى و داوطلبانه رضايت آكاهانه كرفته شد. 
جدول ا. ويثخى هاى جمعيتشناختى دانش آموزان پٍر در دو كَروه مداخله و كنترل

\begin{tabular}{|c|c|c|c|c|c|c|}
\hline \multirow{3}{*}{$\begin{array}{c}\text { p-value } \\
\text { آزمون تى مستقل p } \\
\text { p = / V }\end{array}$} & \multicolumn{4}{|c|}{ سن (ميانغين 土 انحراف معيار) } & \multirow{3}{*}{\multicolumn{2}{|c|}{ 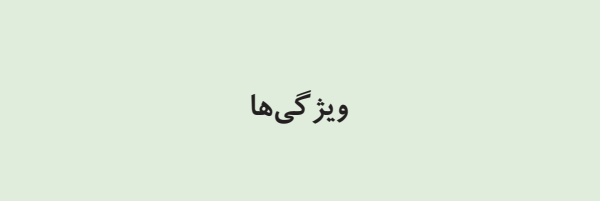 }} \\
\hline & \multirow{2}{*}{\multicolumn{2}{|c|}{ 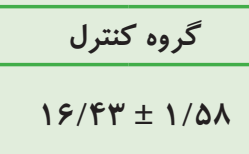 }} & \multirow{2}{*}{\multicolumn{2}{|c|}{ 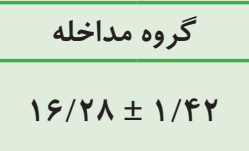 }} & & \\
\hline & & & & & & \\
\hline \multirow{4}{*}{$* \mathrm{p}=\cdot / \mathrm{qq}$} & $p / r q$ & s & r/^ৎ & r & 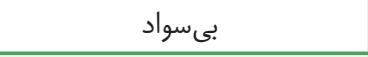 & \multirow{4}{*}{ تحصيلات سريرست } \\
\hline & $\mathrm{V} / \wedge \Delta$ & 11 & $G / F T$ & 9 & زير ديڤلم & \\
\hline & $\mid r / \wedge s$ & 11 & 10 & r) & 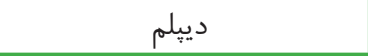 & \\
\hline & Vo & $1 \cdot 0$ & $V \Delta / V 1$ & 1.9 & بالاتر از دييلم & \\
\hline \multirow{4}{*}{$\mathrm{p}=\cdot / r \mid$} & $19 / 79$ & $r v$ & $r \cdot / V I$ & rq & 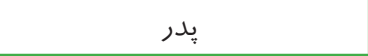 & \multirow{4}{*}{ سريرست خانواده } \\
\hline & $1 \cdot$ & if & $|r /| F$ & IV & 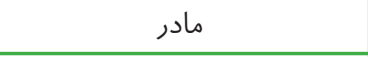 & \\
\hline & 90 & 91 & $G \cdot / V r$ & 10 & 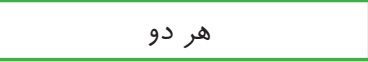 & \\
\hline & $\Delta / \vee 1$ & $\wedge$ & $G / F \mu$ & 9 & 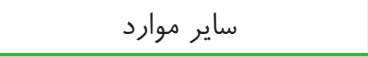 & \\
\hline \multirow{3}{*}{$\mathrm{p}=\cdot / \mu \mathrm{F}$} & $\checkmark \cdot$ & $9 \wedge$ & $V \Psi / \varsigma$ & $1 \cdot r$ & 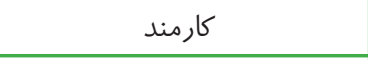 & \multirow{3}{*}{ شغل سريرست } \\
\hline & $I V / I F$ & rF & $10 / V$ & rr & شغل آزاد & \\
\hline & $\mid r / \wedge s$ & 11 & $1 \cdot / V$ & 10 & 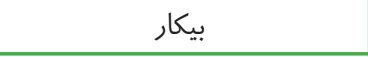 & \\
\hline \multirow{3}{*}{$\mathrm{p}=\cdot|4|$} & $r \cdot / V I$ & pr & $r r / I F$ & $r \Delta$ & بإين & \multirow{3}{*}{ خر آمد سريرست } \\
\hline & $\mathrm{rV} / \mathrm{lf}$ & $\Delta r$ & rV/As & $\Delta r$ & 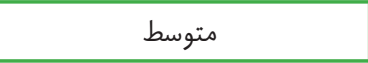 & \\
\hline & rr/IF & io & r. & pr & خوب & \\
\hline \multirow{3}{*}{$\mathrm{p}=\cdot / / 1$} & $\Delta r / \Delta V$ & vo & $G r / I F$ & $\wedge \vee$ & بله & \multirow{3}{*}{ سابقه مصرف سيخار } \\
\hline & rV/AS & rq & $r r / I F$ & ri & 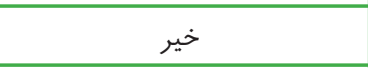 & \\
\hline & $1 N / \Delta V$ & rs & $10 / V r$ & $r r$ & اطلاعى ندارم & \\
\hline \multirow{2}{*}{$\mathrm{p}=\cdot / / q q$} & $p q / r q$ & 99 & $\Delta r / I F$ & $V^{\mu}$ & بله & \multirow{2}{*}{ سابقه مصرف سيخار } \\
\hline & $0 \cdot / V I$ & VI & FV/As & $S V$ & 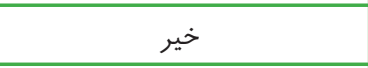 & \\
\hline \multirow{2}{*}{$\mathrm{p}=\cdot / r V$} & $F V / I F$ & s૬ & $F \wedge / \Delta V$ & $9 \wedge$ & بله & \multirow{2}{*}{ داشتن دوست } \\
\hline & $\Delta r / \Lambda S$ & $V F$ & $\Delta 1 / F \mu$ & Vr & خير & \\
\hline $\mathrm{p}=\cdot / \mathrm{VF}^{\mathrm{F}}$ & $p / r q$ & 4 & $\Delta$ & $\checkmark$ & 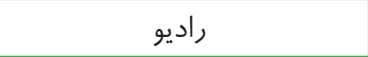 & \multirow{10}{*}{ منابع كسب اطلاعات } \\
\hline $\mathrm{p}=\cdot / \mu r$ & $\Psi \vee / \wedge \varepsilon$ & $s V$ & $F \Delta / V 1$ & $s q$ & 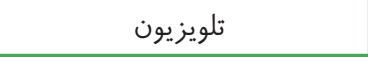 & \\
\hline $\mathrm{p}=\cdot / \varsigma \wedge$ & $1 r / \Delta V$ & 19 & 10 & rI & كتاب & \\
\hline $\mathrm{p}=\cdot / \vee q$ & $\mid r / \wedge s$ & 11 & $|r /| F$ & IV & روزنامه و مجلات & \\
\hline $\mathrm{p}=\cdot / \mu \mathrm{r}$ & 10 & rl & $I V / I F$ & rF & 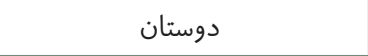 & \\
\hline $\mathrm{p}=\cdot / 41$ & IV/AS & ro & $|\Delta / V|$ & $r r$ & مشاورين و معلمين مدرسه & \\
\hline $\mathrm{p}=\cdot / \mathrm{V} V$ & $q / r q$ & ir & 1. & If & اعضاى خانواده & \\
\hline $\mathrm{p}=\cdot / \Delta \mu$ & $|r /| F$ & IV & $1 r / \Delta V$ & 19 & كار كنان مر كز بهداشتى - درمانى & \\
\hline $\mathrm{p}=\cdot / \mathrm{\wedge} \wedge$ & $r r / \wedge s$ & rr & $r F / r q$ & mp & 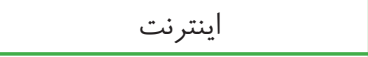 & \\
\hline$p=\cdot / \mu q$ & $I V / I F$ & rF & $19 / 49$ & rV & همه موارد فوق & \\
\hline
\end{tabular}




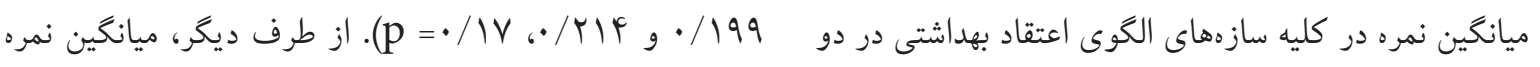

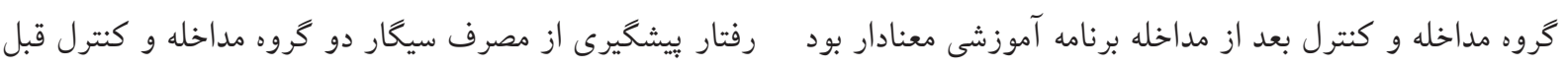

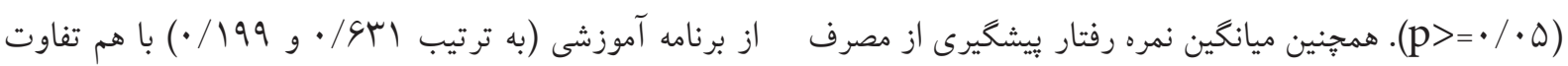

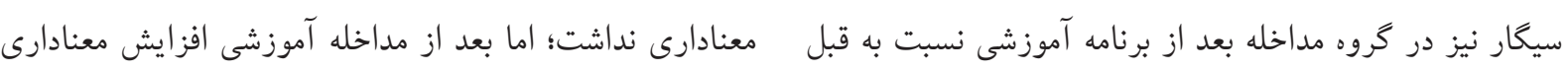

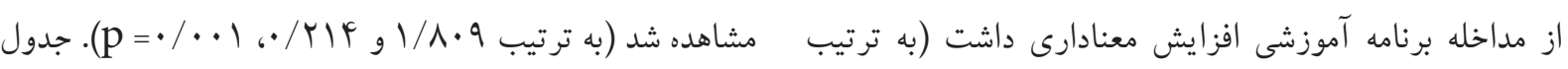

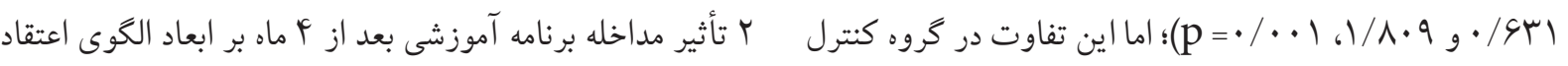

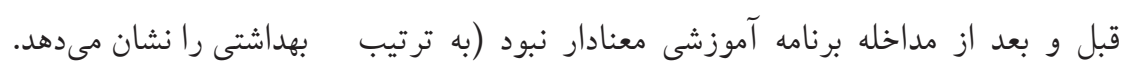

جدول r. ميانگين نمره اجزاى الكَوى اعتقاد بهداشتى و رفتار مصرف سيكار در كَروههاى مداخله و كنترل قبل و أ ماه بعد از مداخله برنامه آموزشى

\begin{tabular}{|c|c|c|c|c|c|c|}
\hline \multirow{3}{*}{$\mathbf{p}$} & \multicolumn{4}{|c|}{ كروه } & \multirow{3}{*}{ زمان مداخله } & \multirow{3}{*}{ نام متغير } \\
\hline & \multicolumn{2}{|c|}{ كنترل } & \multicolumn{2}{|c|}{ مداخله } & & \\
\hline & انحراف معيار & ميانگين & انحراف معيار & ميانگين & & \\
\hline$\cdot / r \mid$ & $\cdot / \pi \Delta$ & $r / 9 q$ & $\cdot / \mu r$ & $r / V I$ & قبل از مداخله & \multirow{3}{*}{ حساسيت درك شده } \\
\hline \multirow[t]{2}{*}{.$/ .1$} & 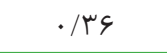 & $r / V$ & $\cdot / \mu r$ & $F / \wedge F$ & بعد از مداخله & \\
\hline & \multicolumn{2}{|c|}{.$/ 11$} & \multicolumn{2}{|c|}{$.1 \cdot 10$} & $\mathrm{p}$ & \\
\hline.$/ 1 \mathrm{~V}$ & $\cdot / r \Lambda$ & $r / \mu \Delta$ & $\cdot / r V$ & $r / \mu V$ & قبل از مداخله & \multirow{3}{*}{ شدت دركشده } \\
\hline \multirow[t]{2}{*}{.$/ r$} & $\cdot / T Y I$ & $r / \mu s$ & $\cdot / \mu 1$ & $r / 01$ & بعد از مداخله & \\
\hline & \multicolumn{2}{|c|}{.$/ 41$} & \multicolumn{2}{|c|}{.$/ \mu p$} & $\mathrm{p}$ & \\
\hline$\cdot / r V$ & $\cdot / \mu r$ & $r / \Delta r$ & $\cdot|r|$ & $r / \Delta Q$ & قبل از مداخله & \multirow{3}{*}{ تهديد دركشده } \\
\hline \multirow[t]{2}{*}{.$/ .1$} & 每/ & $r / F q$ & س או/. & $r / 9 \Lambda$ & بعد از مداخله & \\
\hline & \multicolumn{2}{|c|}{$\cdot / \Delta V$} & \multicolumn{2}{|c|}{.$/ \cdot 11$} & $\mathrm{p}$ & \\
\hline.$/ 8 Y$ & $\cdot / \mu F$ & $r / \Delta \Delta$ & . ro & $r / \Delta F$ & قبل از مداخله & \multirow{3}{*}{ منافع دركشده } \\
\hline \multirow[t]{2}{*}{.$/ p q$} & . & $r / \Delta S$ & G & $r / V r$ & بعد از مداخله & \\
\hline & \multicolumn{2}{|c|}{.$/ \Delta r$} & \multicolumn{2}{|c|}{$\cdot / \cdots 1$} & $\mathrm{p}$ & \\
\hline . & 每/ & $r / F 1$ & $\cdot \mid \mu 1$ & $r / f r$ & قبل از مداخله & \multirow{2}{*}{ موانع دركشده } \\
\hline \multirow[t]{2}{*}{.$/ .1$} & $\cdot /$ r & $r / F F$ & r & $F / s q$ & بعد از مداخله & \\
\hline & \multicolumn{2}{|c|}{$\cdot / 4 V$} & \multicolumn{2}{|c|}{$\cdot / \cdot r$} & $\mathrm{p}$ & \\
\hline.$/ 48$ & $\cdot / r r$ & $1 / 49$ & $\cdot / 11$ & $1 / 01$ & قبل از مداخله & \multirow{2}{*}{ راهنماى عمل } \\
\hline \multirow[t]{2}{*}{.$/ r$} & 每 & $1 / 0$ & $\cdot / r \mid$ & $1 / 99$ & بعد از مداخله & \\
\hline & & & \multicolumn{2}{|c|}{.$/ . .1$} & $\mathrm{p}$ & \\
\hline$\cdot / \cdot V$ &.$/ 199$ & . /OrA & . ITrG & . $\mid$ | & قبل از مداخله & \\
\hline \multirow[t]{2}{*}{.$/ .1$} & $\cdot / r I f$ & $\cdot / \Delta \wedge \mu$ & . IFFO & $1 / 1 \cdot 9$ & بعد از مداخله & رفتار مصرف سيعار \\
\hline & \multicolumn{2}{|c|}{.$/ / V$} & \multicolumn{2}{|c|}{$\cdot / \cdots 1$} & $\mathrm{p}$ & \\
\hline
\end{tabular}


مصرف سيكار داشتند. شيوع مصرف سيكار در نوجوانان كرهاى

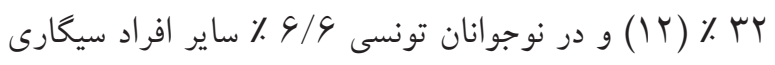
كزارششده است (T (1). در مطالعات متعددى نشان دادهشده كه سن نوجوانان با مراحل استعمال سيكار ارتباط قوى دارد (1F

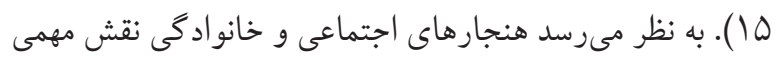

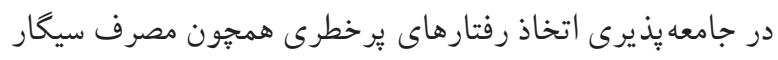

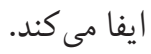

تجزيهوتحليل تشخيصى نشان داد وجود فرد سيگارى در خانواده در تمايل دانشآموزان به استعمال سيعار نقش دارد.

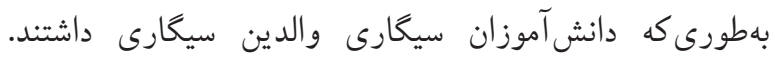
مطالعات متعدد نشان داد كه مصرف سيكار نوجوانان با وجود دودين

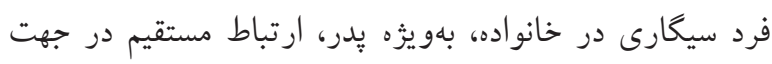

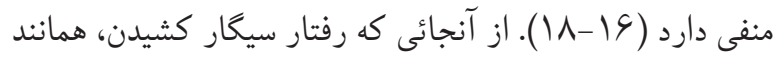

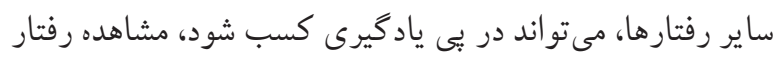

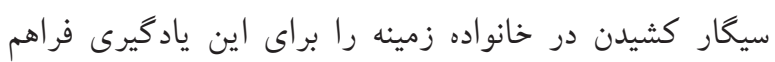
مى كند (19) (19). يكى از متغيرهاى بيشبينى كننده رفتار دريافتِ تائيد و وإن

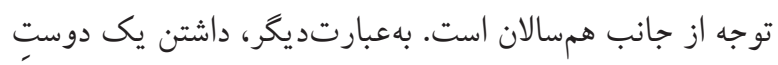
سيخارى نقش مؤثرى در اتخاذ اين رفتار بر خطر دارد. داشتن

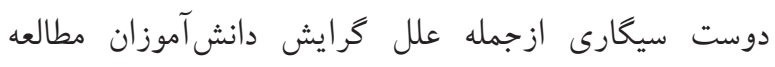

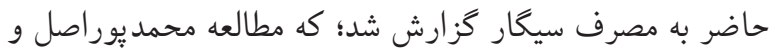

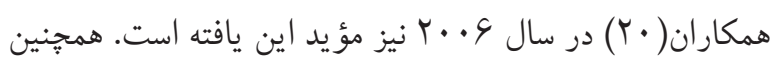

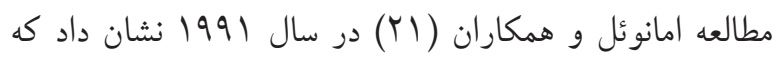
داشتن دوستان و والدين سيخارى از مهمترين عوامل ترغيب نوجوانان به مصرف سيكار است. باينحال، با استفاده از نتايج

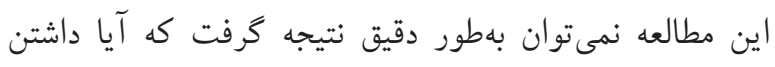

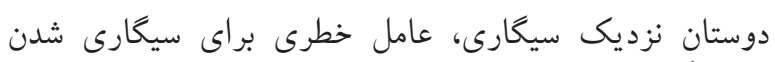

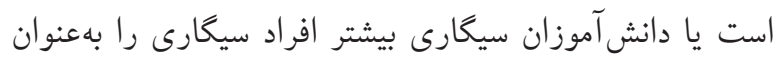

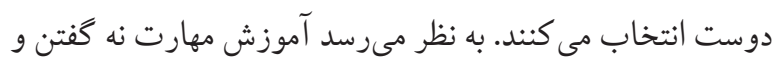

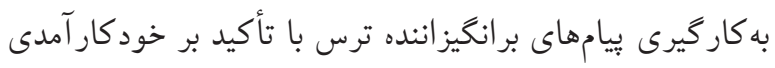

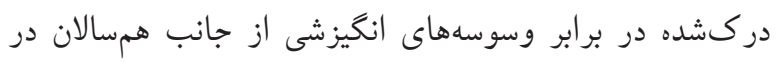

در مطالعه هر رفتار بهتر است به روابط علت و معلولى توجه خاص داشت. رفتار افراد منتج از عوامل متفاوت و درعين حال

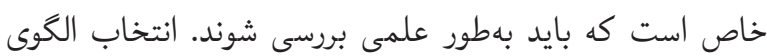

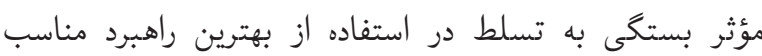

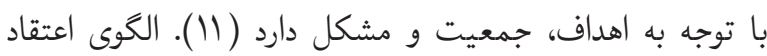

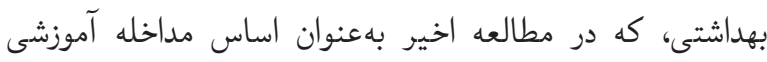
بكار رفته است، در مطالعات مختلف در زمينه مداخلات تغيير

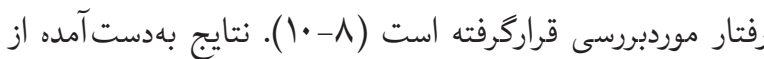
مطالعه حاضر نشاندهنده كارايى اين الكو در خصوص مداخلات تغيير رفتارهاى برخطر نظير ييشگيرى از مصرف سيگار در گروه جمعيتى نوجوانان است.

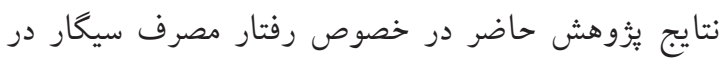

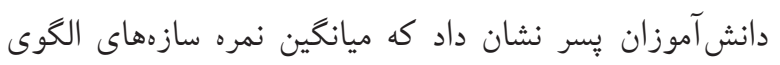

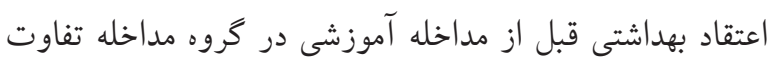

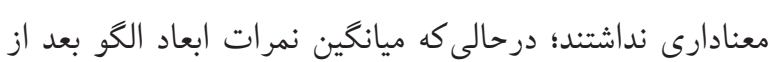

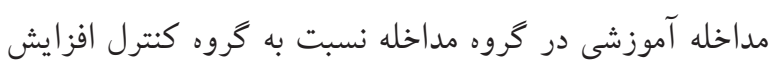

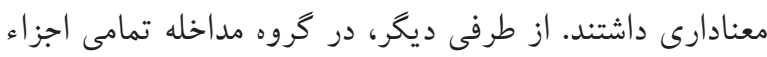

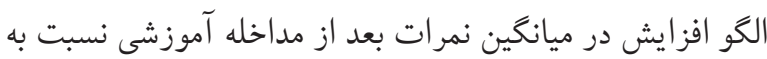
قبل از مداخله داشتند. اين درصورتى است كه هيجيك از اجزاء الكوى اعتقاد بهداشتى در كروه كنترل تفاوتى ازنظر ميانكين

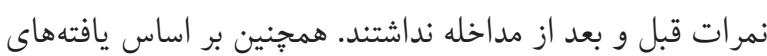

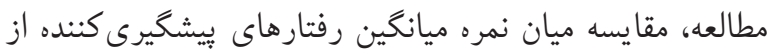

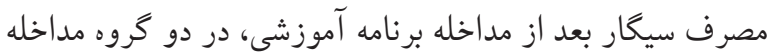
و كنترل، ازنظر آمارى تفاوت معنادارى داشت؛ كه نشاندهنده

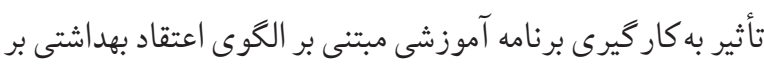

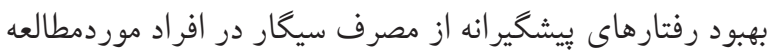
است.

شيوع استعمال سيگار در اين مطالعه در مقايسه با مطالعاتى

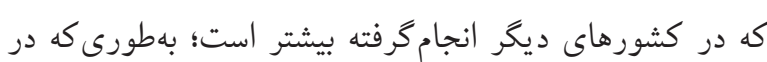

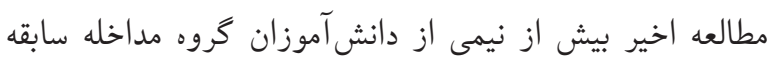


متناسب با موضوع مورد آموزش بوده است. با توجه به اهميت نقش مداخلات آموزشى در ييشخيرى از رفتارهاى يرخطرى همجڤون مصرف سيگار بين دانش آموزان و با در نظر كرفتن اين كه سيگار زمينه شروع وابستخى به ساير مواد اعتيادآور است، ضرورت به كاركيرى مداخلات آموزشى نظريهمحور در زمينههاى مختلف له و با به كاركيرى رويكردهاى متناسب بيشازبيش از اولويتهاى بهداشتى جامعه محسوب شود.

از محدوديتهاى يثوهش اخير تمايل نداشتن برخى از دانش آموزان براى مشاركت در مطالعه بود. از طرفى، با توجه

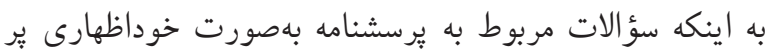
شده است، در بعضى از نمونههاى احتمال صحيح بيان نشدن در خصوص سابقه مصرف سيعار وجود دارد.

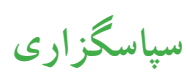

هزينه مطالعه اخير توسط دانشكده بهداشت دانشخاه علوم يزشكى تهران يرداختشده است. از طرفى از سازمان آموزشويرورش شهرستان نوشهر و كليه دانش آموزان كرامى كه در اجراى اين

$$
\text { يثوهش همكارى كردند تشكر و قدردانى مىشود. }
$$

\section{References:}

1. Puberty and adolescence. MedlinePlus. Archived from the original on April 3, 2013. Retrieved July 22, 2014.

2. Edlin G, Golanty E. Health and Wellness. 8th ed. Sudbury MA: Jones and Bartlett; 2004. P. 354.

3. Prevalence of tobacco use. Available at: www.who.int/ gho/tobacco/use/en access in 2016/1/11.

4. Mohammadi N. Schedul of Health Education. Tehran: Mehrvash Publications; 2005. P. 277, 395. [Persian]

5. Shojaeezadeh D. Study of behavioral models in health education. Tehran: Assistance of Ministry of Health, 2000. P. 29-30. [Persian]

6. Vahedian-Shahroodi M, Elaheh L-m, Esmaily $H$, Tehrani $\mathrm{H}$, Hamidreza $\mathrm{M}-\mathrm{H}$. Prediction of osteoporosis preventive behaviors using the Health Belief Model. Iranian Journal of Health Education and Health Promotion. 2014;2(3):199207.

7. Norman P, Brain K. An application of the health belief model to the prediction of breast self-examination in a
ييشگيرى از مصرف سيخار در بين نوجوانان مقاطع راهنمايى و دبيرستان مؤثر باشد.

تلفيق قوانين با اقدامات زيربنايى مبتنى بر ياددهى و يادگيرى

اجتماعى، مىتواند باعث كاهش و كنترل مصرف دخانيات شود. استعمال سيعار موضوعى نيست كه فقط با دستور العمل و ضوابط مئ حلوفصل شود. تصويب قوانينى كه قابليت اجرايي داشته باشد و نيز برخى محدوديتهاى منطقى همانند نكشيدن سيگار در

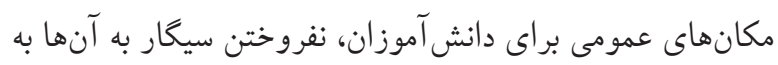
همراه آموزشهاى صحيح بر اساس الكوها و روشهاى متناسب با ويثزى هاى شخصيتى دانشآموزان، بهويث در سنين يايينتر، مى تواند مثمر ثمر باشد (Y)). يافته (Y) مطالعه رحيمى كيان و

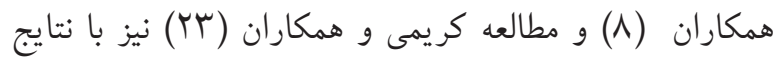
يثوهش حاضر مطابقت دارد و نشاندهنده مؤثر بودن مداخله آموزشى مبتنى بر الكوى اعتقاد بهداشتى در انجام اقدامات ييشگير انه است.

نتيجهذ كيرى: اجراى مداخله آموزشى مبتنى بر الكوى اعتقاد بهداشتى سبب بهبود رفتار ييشگيرانه از مصرف سيگار در دانش آموزان كروه مداخله شده است. بنابراين، مىتوان اظهار

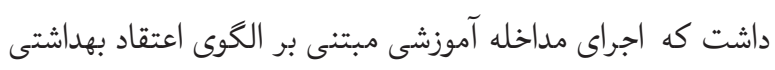

national sample of women with a family history of breast cancer. Institute of Medical Genetics, University of Wales College of Medicine, UK. Available at: http://userpage. fuberlin. de/ health/materials/normanb.pdf.

8. Rahimikian F, Mirmohamadali M, Mehran A, Aboozari K, Salmaani Barough N. Effect of Education Designed based on Health Belief Model on Choosing Delivery Mode. Hayat, Journal of Faculty of Nursing and Midwifery, 2009; 14(3-4): 25-32. [Persian]

9. Hazavehei SM, Taghdisi MH, Saidi M. Application of the Health Belief Model for osteoporosis prevention among middle school girl students, Garmsar, Iran. Educ Health (Abingdon). 2007 May; 20(1): 23. [Persian]

10. Sharifirad GhR, Hazavehei MM, Hasanzadeh A, Daneshamouz A. The effect of health educationbased on health belief model on preventive actions of smoking in grade one, middle school students. Arak Medical University Journal (Rahavard Danesh). 2007; 10(1): 1-8. [Persian] 
11. Allahverdipour H. Passing from traditional health education to achieving theory- based health education programs. Professional Journal Health Education and Health Promotion 2004; 1(3):75- 79. [Persian]

12. Park S, Kim J. Association between smoking and suicidal behaviors among adolescents in the republic of Korea. J Addict Nurs. 2015; 26(4):175-83.

13. Fakhfakh R, Jaidane I, Hsairi M, Ben Hamida AM. [Cigarette smoking initiation among Tunisian adolescents: Risk and protective factors]. Rev Epidemiol Sante Publique. 2015; 63(6):369-79.

14. Nikaj S, Chaloupka F. School personnel smoking, school-level policies, and adolescent smoking in lowand middle-income countries. Tob Control. 2015 Oct 30. pii: tobaccocontrol-2015-052531. doi: 10.1136/ tobaccocontrol-2015-052531. [Epub ahead of print]

15. Mason M, Mennis J, Way T, Lanza S, Russell M, Zaharakis $\mathrm{N}$. Time-varying effects of a text-based smoking cessation intervention for urban adolescents. Drug Alcohol Depend. 2015; 157:99-105.

16. Kawabata T, Shimai S, Nishioka N. The relationship between smoking behavior and self- esteem among elementary and junior high school students. Nippon Koshu Eisei Zasshi 1998; 45(1): 15-26.

17. Hoek J, Gendall P. Self-Esteem: The key to smoke-free youth? Australian and New Zealand Marketing Academy Conference, 2001.

18. Metinta S. Nuhoglu S. Metinta M. Smoking patterns of university students in Eskiehir, Turkey. Public Health 1998; 4:261- 264.

19. Bandura, A. Social Learning Theory. Englewood Cliffs, NJ: Prentice Hall. 1977.

20. Mohammadpoorasl A, Fakhari A, Rostami F, Tabatabayi vakili S M. Prevalence cigarette smoking and relative personal-invironmental factors among adolescence in Tabriz. J Med Council I.R.I, 2006; 24(3): 263-270. [Persian]

21. Emmaunuel SC, Hock, Chen AJ. Cigarette smoking among school children in Singapore. Singapore Med J 1991. 32(4).233-7.

22. Hatami-Zadeh N, Ziaei P, Dolatabadi Sh, Vameghi R, Vasseghi S. Evaluation of Tehran pre-university students awareness of effect of cigarette smoking. Iranian Journal of Psychiatry and Clinical Psychology 2003;9(33):71-78. [Persian]

23. Karimy M, Hasani M, Khoram R, Ghaffari M, Niknami Sh. The Effect of Education, Based on Health Belief Model on Breast Self- Examination in Health Liaisons of Zarandieh City. Zahedan Journal of Research in Medical Sciences, (Tabib-eshargh). 2008; 10(4): 283-291. [Persian] 